\title{
Commentary Lost in translation? The pursuit of lung-protective ventilation
} Andrew T Jones

\author{
Department of Intensive Care Medicine, 1st Floor East Wing, St Thomas's Hospital, Westminster Bridge Road, London SE1 7EH, UK
}

Corresponding author: Andrew T Jones, Andrew.Jones@gstt.nhs.uk

Published: 31 March 2008

Critical Care 2008, 12:122 (doi:10.1186/cc6828)

This article is online at http://ccforum.com/content/12/2/122

(C) 2008 BioMed Central Ltd

See related research by The Irish Critical Care Trials Group, http://ccforum.com/content/12/1/R30

\begin{abstract}
Acute lung injury (ALI) and the acute respiratory distress syndrome (ARDS) remain important causes of morbidity and mortality in the critically ill patient, with far-reaching short-term and long-term implications for individual patients and for healthcare providers. It is well accepted that mechanical ventilation can worsen lung injury, potentially worsening systemic organ function, and can thus impact on mortality in acute lung injury (ALI)/ARDS. Unfortunately, although the concept of minimizing such damage via lungprotective ventilatory strategies is widely acknowledged, effective integration of such an approach into clinical practice remains more elusive. The study by the Irish Critical Care Trials Group published in the previous edition of Critical Care describes a 10-week reallife survey of all intensive care unit admissions across Ireland, detailing for the first time the epidemiology of ALI/ARDS in this population and clinician's attempts to deliver lung-protective ventilation. The authors also report hypothesis-generating data on the implications of statin use in this population. The present commentary reviews aspects of this work, with particular attention to the implementation of low-tidal-volume/lung-protective ventilatory strategies in ALI/ARDS.
\end{abstract}

Firstly, my congratulations to those at the Irish Critical Care Trials Group on their paper detailing the epidemiology and ventilatory management of ALI/ARDS across Ireland [1]; the first publication from this recently established clinical research group. The authors also report hypothesis-generating data on the implications of statin use in this population. The present commentary reviews aspects of this work, with particular attention to the implementation of low-tidalvolume/lung-protective ventilatory strategies in ALI/ARDS.

The advantages of multicenter collaborative research are clear to all, but does the influence of such groups extend beyond the individual studies undertaken? Although individual organizations often have differing infrastructures and approaches to study development, planning and funding, they invariably share a cohesive spirit and a mission to improve the care and outcomes of those with critical illness
[2]. As a result, they surely provide fertile environments not only for ongoing education and training in critical care medicine and research methodology, but also a forum for the discussion and advancement of clinical critical care practice.

The data regarding statin use are tantalizing, and add to the growing debate and interest regarding these agents in the critically ill patient [3]. As the authors rightly conclude, the small numbers involved and the modest data collection in this field, require that these data be considered hypothesis generating - albeit in conjunction with existing data supportive of further study and potentially, a therapeutic trial.

The incidence of ALI/ARDS in the study by the Irish Critical Care Trials Group, 27\% of those patients receiving mechanical ventilation $(19 \%$ of all intensive care unit admissions), is comparable with the literature from recent large surveys from both Europe and North America [4,5]. The mortality figures, albeit only the intensive care unit mortality is quoted, seem favourable in comparison with historical data in Europe. Such figures alone, however, require the provision of significant healthcare resources in terms of hospital and critical care services, and the figures mask, or at best make no reference to, the longer-term morbidity attributable to this condition, with its significant direct and indirect healthcare, social and personal costs $[4,6]$. Acknowledging this burden of disease, the authors rightly identify the importance of accurate, up-to-date epidemiological data to inform the design and feasibility of future clinical trials.

Amongst the physiological data presented, the Irish Critical Care Trials Group report no association of the tidal volume or plateau pressure with mortality. Cognizant of some deficiencies in their data collection, they suggest that this is at least in part due to 'relatively good adherence to lung protective ventilation' [1], reasoning that only $5 \%$ of patients received a tidal volume $>12 \mathrm{ml} / \mathrm{kg}$ predicted body weight $(\mathrm{PBW})$ and

$\mathrm{ALI}=$ acute lung injury $\mathrm{ARDS}=$ acute respiratory distress syndrome; $\mathrm{PBW}=$ predicted body weight. 
only $12 \%$ of patients received a plateau pressure $>30 \mathrm{cmH}_{2} \mathrm{O}$. The mean tidal volume was $\sim 8.4 \mathrm{ml} / \mathrm{kg}$ PBW, however, suggesting that a significant number of patients received higher tidal volumes than the accepted upper limit of a low-tidal-volume approach in the Acute Respiratory Distress Syndrome Network ARMA study ( $8 \mathrm{ml} / \mathrm{kg}$ PBW) [7]. Is this truly lung protective, or is this just as far as clinicians were prepared to go? Whatever the answer, the Irish Critical Care Trials Group are not alone [8].

The publication of the Acute Respiratory Distress Syndrome Network (ARDSNet) ARMA study in 2000, with its $22 \%$ relative reduction in mortality with low-tidal-volume ventilation in patients with ALI/ARDS, was generally heralded as a landmark advance in the care of the critically ill patient. Subsequent uptake of this approach, however, has been disappointingly slow [9].

Poor translation of research into clinical practice is not a problem specific to critical care, or indeed to lung protective ventilation, with potential causes and solutions well documented [10]. Furthermore, even where clinicians are willing, significant organizational and clinical barriers exist in implementing what is a complex, multidisciplinary process at the bedside [11]. Translation of evidence to clinical practice may be improved by the adoption of protocols to drive clinical care, although, this may not be as simple as it might first appear. But what of the subsequent concerns voiced about the study design and the aspects of patient safety?

The ARMA study was criticized for comparing two extremes of ventilatory practice (6 ml/kg PBW versus $12 \mathrm{ml} / \mathrm{kg}$ PBW) rather than employing more common and potentially safer practice as a control ( 8 to $10 \mathrm{ml} / \mathrm{kg}$ ). Critics argued that as a result participants were subjected to higher risks, and that the investigators were led to erroneously conclude that ventilation with the lowest tidal volumes is superior [12]. In response, the ARDSNet investigators challenged the methodology of their critic's meta-analysis and reiterated their belief that, at the time the study was instigated, no such standard of ventilatory care existed [13]. In addition, they subsequently reported further data from the ARMA study, detailing benefits of tidal volume and plateau pressure reduction across the range of disease severity and baseline plateau pressures, arguing against the $\mathrm{U}$-shaped relationship for tidal volume and mortality alluded to by their critics $[13,14]$. As the reader is undoubtedly aware, the subsequent repercussions from these events have been significant $[15,16]$, and robust debate continues $[14,17,18]$. It seems highly probable that this perceived uncertainty has impacted on the degree to which low-tidal-volume ventilation has been pursued by practicing clinicians.

Where do we go from here? Clinical education and process management undoubtedly have a role to play, but at what target are clinicians aiming? On reading the current article by the Irish Critical Care Trials Group, some will suggest that, although there has been improvement, there is some way to go before we achieve the evidence-based standard of ventilatory practice in ALI/ARDS. Others, meanwhile, will argue that - based on existing evidence - we may be close to arriving at that standard, and to go lower requires further investigation. Under such circumstances, it would not be surprising if we see relatively little change in the delivered tidal volume in the near future.

\section{Competing interests}

The author declares that they have no competing interests.

\section{References}

1. The Irish Critical Care Trials Group: Acute lung injury and the acute respiratory distress syndrome in Ireland; a prospective audit of epidemiology and management. Crit Care 2008, 12: R30.

2. Cook D, Brower R, Cooper J, Brochard L, Vincent JL: Multicenter clinical research in adult critical care. Crit Care Med 2002, 30: 1636-1643.

3. Craig T, O'Kane CM, McAuley DF: Potential mechanisms by which statins modulate pathogenic mechanisms important in the development of acute lung injury. In 27th Yearbook of Intensive Care and Emergency Medicine. Edited by Vincent JL. Berlin: Springer-Verlag; 2007.

4. Rubenfeld GD, Caldwell E, Peabody E, Weaver J, Martin DP, Neff $M$, Stern EJ, Hudson LD: Incidence and outcomes of acute lung injury. N Engl J Med 2005, 353:1685-1693.

5. Brun-Buisson C, Minelli C, Bertolini G, Brazzi L, Pimentel J, Lewandowski K, Bion J, Romand JA, Villar J, Thorsteinsson A: Epidemiology and outcome of acute lung injury in European intensive care units: results from the ALIVE study. Intensive Care Med 2004, 30:51-61.

6. Herridge MS, Cheung AM, Tansey CM, Matte-Martyn A, DiazGranados N, Al-Saidi F, Cooper AB, Guest CB, Mazer CD, Mehta S, Stewart TE, Barr A, Cook D, Slutsky AS, Canadian Critical Care Trials Group: One-year outcomes in survivors of the acute respiratory distress syndrome. N Engl J Med 2003, 348: 683-693.

7. Acute Respiratory Distress Syndrome Network: Ventilation with lower tidal volumes as compared with traditional tidal volumes for acute lung injury and the acute respiratory distress syndrome. N Engl J Med 2000, 342:1301-1308.

8. Esteban A, Ferguson ND, Meade MO, Frutos-Vivar F, Apezteguia C, Brochard L, Raymondos K, Nin N, Hurtado J, Tomicic V, Gonzalez $M$, Elizalde J, Nightingale $P$, Abroug F, Pelosi $P$, Arabi $Y$, Moreno R, Jibaja M, D'Empaire G, Sandi F, Matamis D, Maria Montanez A, Anzueto A, for the VENTILA Group: Evolution of mechanical ventilation in response to clinical research. $A m \mathrm{~J}$ Respir Crit Care Med 2008, 177:170-177.

9. Weinert CR, Gross CR, Marinelli WA: Impact of randomized trial results on acute lung injury ventilator therapy in teaching hospitals. Am J Respir Crit Care Med 2003, 167:1304-1309.

10. Rubenfeld GD: Implementing effective ventilator practice at the bedside. Curr Opin Crit Care 2004, 10:33-39.

11. Rubenfeld GD, Cooper C, Carter G, Thompson BT, Hudson LD: Barriers to providing lung-protective ventilation to patients with acute lung injury. Crit Care Med 2004, 32:1289-1293.

12. Eichacker PQ, Gerstenberger EP, Banks SM, Cui X, Natanson C: Meta-analysis of acute lung injury and acute respiratory distress syndrome trials testing low tidal volumes. Am J Respir Crit Care Med 2002, 166:1510-1514.

13. Brower RG, Matthay M, Schoenfeld D: Meta-analysis of acute lung injury and acute respiratory distress syndrome trials. $\mathrm{Am}$ $J$ Respir Crit Care Med 2002, 166:1515-1517.

14. Hager DN, Krishnan JA, Hayden DL, Brower RG, ARDS Clinical Trials Network: Tidal volume reduction in patients with acute lung injury when plateau pressures are not high. Am J Respir Crit Care Med 2005, 172:1241-1245.

15. Steinbrook R: How best to ventilate? Trial design and patient safety in studies of the Acute Respiratory Distress Syndrome. 
N Engl J Med 2003, 348:1393-1401.

16. Steinbrook R: Trial design and patient safety - the debate continues. N Engl J Med 2003, 349:629-630.

17. Deans KJ, Minneci PC, Cui X, Banks SM, Natanson C, Eichacker PQ: Mechanical ventilation in ARDS: one size does not fit all. Crit Care Med 2005, 33:1141-1143.

18. Brower R, Thompson BT, ARDS Network Investigators: Tidal volumes in acute respiratory distress syndrome - one size does not fit all. Crit Care Med 2006, 34:263-264. 